\title{
Fourteen Year Surveillance of Nosocomial Infections in Neurology Unit
}

\author{
Recep Tekin ${ }^{\mathrm{a}, \mathrm{d}}$, Tuba Dal ${ }^{\mathrm{b}}$, Mehmet Ugur Cevik ${ }^{\mathrm{c}}$, Fatma Bozkurt ${ }^{\mathrm{a}}$, \\ Ozcan Deveci ${ }^{\mathrm{a}}$, Alicem Tekin ${ }^{\mathrm{b}}$
}

\begin{abstract}
Background: The purpose of this study was to evaluate the longterm data of Neurology Unit and emphasize the importance of hospital infection control.

Methods: This study was performed between January 1997 and December 2010. The surveillance method was active, prospective, and based on laboratory and patient. Active surveillance of nosocomial infections (NIs) was performed by infection control team, using the criteria proposed by the CDC (The Centers for Disease Control and Prevention) and National Nosocomial Infections Surveillance System (NNIS) methodology.
\end{abstract}

Results: During the study period, 435 episodes were detected in 384 patients. The overall incidence rates (NI/100) and incidence densities (NI/1,000 days of stay) of NIs were 3.7\% (range $1.0-7.7$ ) and 3.2/1,000 patient-day (range $0.8-7.2 / 1,000$ ), respectively. The most common nosocomial infection by primary site was urinary tract infections (32\%), and pneumonia (25.1\%). The most prevalent microorganisms were coagulase-negative staphylococci $(39.4 \%)$, Escherichia coli (18\%), Staphylococcus aureus (10\%) and Klebsiella spp. $(9.9 \%)$.

Conclusions: We conclude that development of nosocomial infection will be prevented by monitoring the patients in fully-equipped intensive care units, the rapid termination of invasive procedures,

Manuscript accepted for publication June 18, 2012

${ }^{a}$ Department of Infectious Disease and Clinical Microbiology, Faculty of Medicine, Dicle University, Diyarbakir, Turkey

${ }^{\mathrm{b}}$ Department of Microbiology, Faculty of Medicine, Dicle University, Diyarbakir, Turkey

${ }^{\mathrm{c}}$ Department of Neurology, Faculty of Medicine, Dicle University, Diyarbakir, Turkey

${ }^{\mathrm{d}}$ Corresponding author: Recep Tekin, Department of Infectious Disease, Faculty of Medicine of Dicle University, Yenisehir 21280 Diyarbaklr, Turkey.Email: rectek21@hotmail.com

doi:10.4021/jnr113w appropriate antibiotic therapy and discharging the patient, significantly.

Keywords: Epidemiology; Nosocomial infections; Neurological unit surveillance

\section{Introduction}

Nosocomial infections (NIs) cause important morbidity and mortality, and have a considerable impact on healthcare costs [1]. Nosocomial infection rates mainly depend on the severity of illness and the exposure to invasive devices (especially ventilator use, central venous catheters, urinary catheters). Effective infection control programmes, such as surveillance, can reduce the infection rate by up to $32 \%$. Surveillance of NI provides data useful for identifying patients who are infected, for determining the site of infection, and for identifying factors that contribute to the incidence of NI [2]. With a careful implementation of infection control and surveillance program, shown to reduce a substantial number of the hospital infections [3].

Due to patient with neurological disorders need hospitalize for a long time and an excessive number of invasive application, nosocomial infections are encountered in neurology unit, frequently [2]. There are few studies related to long-term follow-up and evaluation of hospital infections in neurology unit [2].

We aimed to assess the rate of NIs, frequency of nosocomial pathogens and antimicrobial susceptibility changes in a neurology unit over a fourteen-year period in present study.

\section{Material and Method}

This study was performed between January 1997 and December 2010 in Dicle University Hospital (DUH) which is a region tranmission center in the southeastern of Turkey, with 1,150 beds, of which have 35 beds in Neurology Clinics and eight of these beds belong to intensive care unit (ICU). A total of 11,772 patients who have cerebrovascular disease 
Table 1. The Rates of Nosocomial Infections in Dicle University Hospital Neurology Unit for 1997 - 2010 (\%).

\begin{tabular}{|c|c|c|c|c|c|}
\hline Year & $\begin{array}{l}\text { Number of } \\
\text { hospitalized patients }\end{array}$ & $\begin{array}{l}\text { Number of } \\
\text { hospitalized days }\end{array}$ & $\begin{array}{l}\text { Number } \\
\text { of NIs }\end{array}$ & $\begin{array}{l}\text { Incidence } \\
\text { rates of NIs }\end{array}$ & $\begin{array}{l}\text { Incidence } \\
\text { densities of NIs }\end{array}$ \\
\hline 1997 & 556 & 7,606 & 6 & 1.0 & 0.8 \\
\hline 1998 & 612 & 6,134 & 7 & 1.1 & 1.1 \\
\hline 1999 & 703 & 8,008 & 20 & 2.9 & 2.5 \\
\hline 2000 & 762 & 8,570 & 38 & 5.0 & 4.4 \\
\hline 2001 & 786 & 7,998 & 23 & 3.0 & 2.9 \\
\hline 2002 & 744 & 8,009 & 35 & 4.7 & 4.4 \\
\hline 2003 & 747 & 8,527 & 19 & 2.5 & 2.2 \\
\hline 2004 & 899 & 9,149 & 42 & 4.7 & 4.6 \\
\hline 2005 & 1,035 & 10,229 & 21 & 2.0 & 2.1 \\
\hline 2006 & 1,061 & 11,376 & 82 & 7.7 & 7.2 \\
\hline 2007 & 1,124 & 12,395 & 20 & 1.8 & 1.6 \\
\hline 2008 & 1,039 & 12,614 & 36 & 3.5 & 2.9 \\
\hline 2009 & 757 & 12,392 & 56 & 7.4 & 4.5 \\
\hline 2010 & 947 & 10,985 & 30 & 3.2 & 2.7 \\
\hline Total & 11,772 & 133,992 & 435 & 3.7 & 3.2 \\
\hline
\end{tabular}

and epilepsy were included in present study. The surveillance method was active, and based on laboratory and patient. Active surveillance of NIs was performed by infection control team, using the criteria proposed by the CDC (The Centers for Disease Control and Prevention) and National Nosocomial Infections Surveillance System (NNIS) methodology. Culture results obtained from hospitalized patients were evaluated and reviewed by two infection control nurses along with three times week bedside visits. All cases with NI were recorded by using a standard data collection form that included the patient's name, age, sex, microbiological culture results, underlying conditions, risk factors for NIs, interventions at the hospital, reason for hospitalization, and treatment for all patients. Medical and nursing notes, microbiology reports, temperature charts, and antibiotic treatment charts of patients with NI were reviewed and all of data was evaluated by the infection control team. NIs were classified as urinary tract infections (UTIs), decubitus, pneumonia, catheter related bloodstream infections (CRBIs), bloodstream infection (BSIs), sepsis, and the others (meningitis, surgery site infection).

Everyday, the data of nosocomial microorganisms were collected from Hospital Core Laboratory and Infection Diseases Department Laboratory. Antimicrobial susceptibility 
Table 2. The Distribution of Nosocomial Infection Types for 1997 - 2010 (\%)

\begin{tabular}{|c|c|c|c|c|}
\hline Type of NI & $\begin{array}{l}\text { Number of } \\
\text { infections }\end{array}$ & $\begin{array}{l}\text { Percent of total } \\
\text { infections }\end{array}$ & $\begin{array}{l}\text { Incidence } \\
\text { rates }\end{array}$ & $\begin{array}{l}\text { Incidence } \\
\text { densities }\end{array}$ \\
\hline Urinary tract infection & 139 & 32 & 1.2 & 1.0 \\
\hline Pneumonia & 109 & 25.1 & 0.8 & 0.8 \\
\hline Decubitis & 82 & 18.8 & 0.7 & 0.6 \\
\hline Bloodstream infection & 75 & 17.2 & 0.6 & 0.6 \\
\hline Ventilator-Associated Pneumonia & 20 & 4.6 & 0.2 & 0.1 \\
\hline Catheter infection & 7 & 1.6 & 0.06 & 0.05 \\
\hline Others* & 3 & 0.7 & 0.03 & 0.02 \\
\hline Total & 435 & 100.0 & 3.7 & 3.2 \\
\hline
\end{tabular}

*( Surgery site infection, meningitis).

tests were performed to the accordance with the recommendations Clinical Laboratory Standards Institute (CLSI). Incidence rate was defined as the number of NIs per 100 patients discharged during the period of surveillance. The incidence density of NI was calculated on the basis of 1,000 days of stay in hospital.

\section{Results}

During the fourteen-year period, 435 nosocomial infection (NI) episodes were detected in 384 patients out of 11,772 in patients. The mean age of the patient population was 60.4 years (range 14 - 100) with 181 female and 203 male. The mean length of stay in the hospital was 34.3 days (range 3 - 100). The overall incidence rates (NI/100) and incidence densities (NI/1000 days of stay) of NIs were $3.7 \%$ (range 1.0 - 7.7) and 3.2/1,000 patient-day (range 0.8 - 7.2/1,000), respectively (Table 1). Regardless of the year of surveillance, the three most commonly detected NIs were urinary tract infections (UTIs), pneumonia and decubitus (Table 2). The most common pathogens were coagulase-negative staphylococci (n:116), Escherichia coli (n:53), Staphylococcus aureus (n:30), Klebsiella (n:29) and Pseudomonas aeruginosa (n:19) (Table 1). Coagulase-negative staphylococci isolates were the most common nosocomial pathogens for all fourteen years. Colistin, meropenem and amikacin were the most effective agents against Gram-negative bacteria (Table 2).
The meticillin resistance among $S$. aureus isolates was $81 \%$ and all of these isolates were sensitive to vancomycin and linezolid (Table 3).

\section{Discussion}

Nosocomial infections remain a major health problem since the 19th century although the infection control programs, worldwide. Nosocomial infections which especially encountered in neurology units (NUs) and neurological intensive care units are associated with increased morbidity, mortality and hospital costs. Therefore, the interests in these infections is increasing with each passing day $[1,4,5]$.

Patients hospitalized due to stroke are usually elderly patients and they have additional risk factors such as immobility, debilitating and intensive use of steroids. For this reason, these patients form a group of patients at high risk for nosocomial infection development [4].

The surveillance studies regarding nosocomial infections in neurology and neurological intensive care units have been under investigation worldwide. Zolldann et al found that the incidence of infections in NICU was 18.5/100 and incidence density was $25.7 / 1,000$. In another study Dettenkofer et al declared the incidence and incidence density as $24.2 / 100$ and 25.0/1,000, respectively in NICU $[2,6]$. Incidence of infections in neurology unit and NICU was found to be 3.6 - $30.8 \%$ in different studies from Turkey $[1,5,7]$. In pres- 
Table 3. The Distribution of Nosocomial Pathogens for 1997 - 2010 (\%).

\begin{tabular}{ll} 
Microorganizm name & Number MO (\%) \\
\hline Coagulase-negative staphylococci & $116(39.4)$ \\
Escherichia coli & $53(18)$ \\
Staphylococcus aureus & $30(10.2)$ \\
Klebsiella spp. & $29(9.9)$ \\
Pseudomonas aeruginosa & $19(6.5)$ \\
Enterobacter spp. & $12(4.1)$ \\
Enterococcus & $11(3.7)$ \\
Acinetobacter spp. & $11(3.7)$ \\
Candida & $4(1.4)$ \\
Citrobacter spp. & $294(100 \%)$ \\
Other & $7(2.4)$ \\
\hline
\end{tabular}

ent study the overall incidence rates $(\mathrm{NI} / 100)$ and incidence densities (NI/1,000 days of stay) of NIs were $3.7 \%$ (range 1.0 - 7.7) and 3.2/1,000 patient-day (range $0.8-7.2 / 1,000$ ), respectively. These rates were low but consistent with other studies from literature. In addition ventilator-associated pneumonia, urinary catheter related urinary tract infections and central venous catheter-related bloodstream infection are the most common nosocomial infections in neurology units and NICU, worldwide [7].

Nosocomial infections have been estimated to develop in about one third of patients with acute stroke, most commonly affecting the urinary tract and the lungs [8]. In addition neurology-ICU-treated patients with acute stroke must be considered a high-risk group for the development of pneumonia. Stroke-associated pneumonia was reported as $21.4 \%$ in a prospective study and the results suggested that a considerable number of stroke-associated pneumonia cases are community-acquired soon after stroke onset [3]. Ventilator-associated pneumonia, is the most common nosocomial infection among medical intensive care unit patients and is associated with increased mortality and length of stay. Neurologic disease is a risk factor for ventilator-associated pneu- monia development, but the relationship between ventilatorassociated pneumonia and outcomes in patients admitted to the ICU for neurologic reasons remains largely unknown [9].

Urinary tract infections (32\%), pneumonia (25.1\%) and primary bloodstream infections $(17.2 \%)$ were the three most common types of infection in our study. In the study from Germany, pneumonia (11.7\%), urinary tract infections $(8.7 \%)$ and primary bloodstream infections $(1.4 \%)$ were reported as the three most common infections [2]. Pneumonia $(34 \%)$, urinary tract infection (28\%) and sepsis (10\%) were the most common site-specific infections reported from India $[10,11]$. Another study performed in a neurology ICU in Austria rates of nosocomial bacteraemia, pneumonia and urinary tract infection reported as $37.3 \%, 27.4 \%$ and $25.5 \%$, respectively $[10,12]$.

In present study the most common nosocomial infection by primary site were urinary tract infections $(32 \%)$, and pneumonia (25.1\%).

Although a direct relationship between nosocomial infection and mortality in intensive care unit (ICU) patients has not always been demonstrated formally, it is possible to conclude that nosocomial infections increase the risk of 
death in critically ill patients. A more precise analysis indicates that: 1) this effect is highly probable for pneumonia, doubtful for bacteremia, and uncertain for urinary tract infection; 2) risk increases with duration of stay in the ICU; 3) bacterial etiology modifies the risk; and 4) this effect is stronger in less severely ill patients, probably because the severity of underlying disease remains the most significant factor [13].

In the German study, the most common micro-organisms isolated were Acinetobacter baumannii, Staphylococcus aureus and Escherichia coli. This was a reflection of an outbreak due to A. baumannii [14]. In general, gram-negative bacilli have been implicated in $40 \%$ to $60 \%$, Staphylococcus aureus in $20 \%$ to $40 \%$, and anaerobic bacteria in $0 \%$ to $35 \%$ of cases [15]. In our study most frequently isolated bacteria were Coagulase-negative staphylococci (39.4\%), Escherichia coli (18\%), Staphylococcus aureus (10.2\%) and Klebsiella spp. $(9.9 \%)$, respectively. These findings suggest that the incidence of infections due to gram-positive agents in our hospital neurology services. Reason for the increasing incidence of coagulase-negative staphylococci, may be widespread catheter applications in our hospital and Staphylococcus aureus, gram-negative bacteria may be acquired by exogenous sources such as the hands of hospital personnel $[3,16]$. In addition the high frequency of aerobic gram-negative pathogens may point to endogenous lung colonization after aspiration of oropharynx secretions.

In conclusion because of prolonged hospital stay, invasive procedures, and inappropriate use of antibiotics, treatment of hospital infections became more difficult currently. This study showed that special efforts should be made to prevent nosocomial infection and we think that monitoring the patients in fully-equipped intensive care units, the rapid termination of invasive procedures, appropriate antibiotic therapy and discharging the patient as soon as possible will prevent the development of nosocomial infection, significantly. In addition observance of the corresponding guidelines published by the Centers for Disease Control and Prevention is strongly recommended. As poor hand hygiene is the most significant cause of transmission of NI and importance should be given enough importance to effective staff education.

\section{References}

1. Erdinc FS, Yetkin MA, Ataman Hatipoglu C, Yucel M, Karakoc AE, Cevik MA, Tulek N. Five-year surveillance of nosocomial infections in Ankara Training and Research Hospital. J Hosp Infect. 2006;64(4):391-396.

2. Dettenkofer M, Ebner W, Els T, Babikir R, Lucking C, Pelz K, Ruden H, et al. Surveillance of nosocomial infections in a neurology intensive care unit. J Neurol. 2001;248(11):959-964.

3. Hilker R, Poetter C, Findeisen N, Sobesky J, Jacobs A, Neveling M, Heiss WD. Nosocomial pneumonia after acute stroke: implications for neurological intensive care medicine. Stroke. 2003;34(4):975-981.

4. Shafer SQ, Brust JCM, Healton EB and Mayo JB. Hospital acquired morbidity on a neurology service. Journal of the national medical association 1998;87(1):31-35.

5. Buke C, Biyikli B, Tuncel M, Aydemir S, Tunger A, Sirin H, Sagduyu Kocaman H. Nosocomial Infections in a Neurological Intensive Care Unit. Journal of Neurological Sciences 2009; 26(3): 298-304

6. Zolldann D, Poetter C, Hilker R, Neveling M, Waitschies B, Klein W, Nolden-Koch M, et al. [Periodic surveillance of nosocomial infections in two neurology intensive care units. A valuable tool for quality management in intensive care]. Anaesthesist. 2003;52(8):690-696.

7. ( http://www.rshm.gov.tr/enfeksiyon/dosya/WEBrapor20062009.pdf)

8. Walker AE, Robins M, Weinfeld FD. Clinical findings: the National Survey of Stroke. Stroke 1981;12(suppl 1):13-37

9. Josephson SA, Moheet AM, Gropper MA, Nichols AD, Smith WS. Ventilator-associated pneumonia in a neurologic intensive care unit does not lead to increased mortality. Neurocrit Care. 2010;12(2):155-158.

10. Cevik MA, Yilmaz GR, Erdinc FS, Ucler S, Tulek NE. Relationship between nosocomial infection and mortality in a neurology intensive care unit in Turkey. J Hosp Infect. 2005;59(4):324-330.

11. Khanna N, Arunodaya GR, Umamaheshwar-Rao GS. Infections in the neurology/neurosurgery ICU: a prospective study Neurol India 1999;47 (Suppl. 1):53.

12. Schmutzhard E, Engelhardt K, Beer R, Brossner G, Pfausler B, Spiss H, Unterberger I, et al. Safety and efficacy of a novel intravascular cooling device to control body temperature in neurologic intensive care patients: a prospective pilot study. Crit Care Med. 2002;30(11):2481-2488.

13. Fagon JY, Novara A, Stephan F, Girou E, Safar M. Mortality attributable to nosocomial infections in the ICU. Infect Control Hosp Epidemiol. 1994;15(7):428-434.

14. Vincent JL. Nosocomial infections in adult intensivecare units. Lancet. 2003;361(9374):2068-2077.

15. Craven DE, Steger KA. Hospital-acquired pneumonia: perspectives for the healthcare epidemiologist. Infect Control Hosp Epidemiol. 1997;18(11):783-795.

16. Ustun C, Geyik MF, Aldemir M, Tekin R, Celen MK, Girgin S, et al. Surveillance of Nosocomial Infections in General Surgery Unit: Data of Ten Years Period. Duzce Medical Journal 2010; 12(3): 1-6. 